\title{
Impaired Autoregulation of Blood Flow in Skeletal Muscle and Subcutaneous Tissue in Long-Term Type 1 (Insulin-Dependent) Diabetic Patients with Microangiopathy
}

\author{
I. Faris ${ }^{1}$, H. Vagn Nielsen ${ }^{3}$, O. Henriksen ${ }^{1}$, H.-H.Parving² and N. A. Lassen ${ }^{1}$ \\ 'Department of Clinical Physiology, Bispebjerg Hospital, ${ }^{2}$ Steno Memorial Hospital, Gentofte, and \\ ${ }^{3}$ Department of Medicine F, Herlev Hospital, University of Copenhagen, Denmark
}

\begin{abstract}
Summary. Autoregulation of blood flow was studied in skeletal muscle and subcutaneous tissue in seven Type 1 (insulindependent) diabetic patients (median age: 36 years) with nephropathy and retinopathy and in eight normal subjects of the same age. Blood flow was measured by the local ${ }^{133} \mathrm{Xe}$ washout technique. Reduction in arterial perfusion pressure was produced by elevating the limb 20 and $40 \mathrm{~cm}$ above heart level. Blood flow remained within $10 \%$ of control values when the limb was elevated in normal subjects. In five of the seven
\end{abstract}

diabetic subjects blood flow fell significantly in both tissues when the limb was elevated $40 \mathrm{~cm}$ indicating impaired autoregulation. The results suggest that intrinsic vascular (arteriolar) mechanisms (myogenic and/or metabolic) underlying the normal autoregulatory response are defective in some diabetic patients with microangiopathy.

Key words: Autoregulation, blood flow, ${ }^{133} \mathrm{Xe}$ washout, postural change, diabetic microangiopathy.
Autoregulation of blood flow, i.e. the maintenance of blood flow within narrow limits during changes in perfusion pressure induced by changing arterial pressure, has been demonstrated in many tissues and organs. Much attention has been paid to autoregulation in the brain [1] and the kidney [2] but it has also been demonstrated in human subcutaneous tissue [3] and skeletal muscle. The mechanisms underlying the compensatory changes in vascular (arteriolar) tone during changes in arterial pressure are unknown. The autoregulatory response is unaffected by chronic sympathetic denervation [4] indicating that intrinsic vascular mechanisms are responsible. The major theories invoke changes in myogenic activity [5] or local metabolic factors [6]. Arteriolar tone is influenced by local changes in concentrations of various metabolites including adenosine [7], pyrophosphate [8] and potassium [9]. Furthermore, local changes in oxygen [10] and carbon dioxide tensions [11] may play an important role.

In diabetic subjects cerebral blood flow is less rigidly controlled than in normal subjects, suggesting impaired autoregulation $[12,13]$. Apart from this no information is available on autoregulation in diabetes. The purpose of our study was to determine whether impaired autoregulation was present in skeletal muscle and subcutaneous tissue in long-standing, Type 1 (insulin-dependent) diabetic patients with microangiopathy.
Blood flow was measured by the local isotope washout technique and reduction in perfusion pressure was produced by elevation of the limb.

\section{Patients and Methods}

Seven diabetic patients (two women and five men), aged 25-39 years (median: 36 years) were investigated; all had been fully informed of the nature of the study before giving their consent. The duration of diabetes ranged from 15 to 20 years (median: 18 years). Two patients had proliferative retinopathy and the remaining five had background retinopathy. All had nephropathy defined as persistent proteinuria (range $1.5-4.2 \mathrm{~g} / 24 \mathrm{~h}$; median $1.8 \mathrm{~g} / 24 \mathrm{~h}$ ). Glomerular filtration rate measured with the ${ }^{51} \mathrm{Cr}$-EDTA technique [14] ranged from 54 to $101 \mathrm{ml} / \mathrm{min}$ per $1.73 \mathrm{~m}^{2}$ (median $87 \mathrm{ml} / \mathrm{min}$ per $1.73 \mathrm{~m}^{2}$ ). Peripheral pulses were normal and the ankle systolic pressure was equal to or greater than the arm pressure in all patients. These findings indicate that there was no significant large vessel narrowing. The mean arterial blood pressure was $108 \mathrm{mmHg}$ (range: $97-110 \mathrm{mmHg}$ ). None of the patients were taking drugs except insulin. All had their morning insulin $(07.00 \mathrm{~h})$ and normal breakfast $(07.30 \mathrm{~h})$ at home on the day of the investigation, which started at $13.00 \mathrm{~h}$. No patient had ketonuria during the investigation, when blood glucose ranged from 3.6 to $15.7 \mathrm{mmol} / 1$ (median: $11.1 \mathrm{mmol} / \mathrm{l}$ ).

The control group consisted of eight healthy subjects (two women, six men) aged 33-40 years (median: 36 years).

Blood flow in SC tissue and muscle was measured by the local ${ }^{133} \mathrm{Xe}$ washout technique [15]. ${ }^{133} \mathrm{Xe}$ in saline $(0.1-0.2 \mathrm{ml}, 0.5-1.0 \mathrm{mCi}$ was injected; (a) into the $\mathrm{SC}$ tissue $10 \mathrm{~cm}$ below the head of the fibula; (b) into the upper third of the opposite tibialis anterior muscle). After 


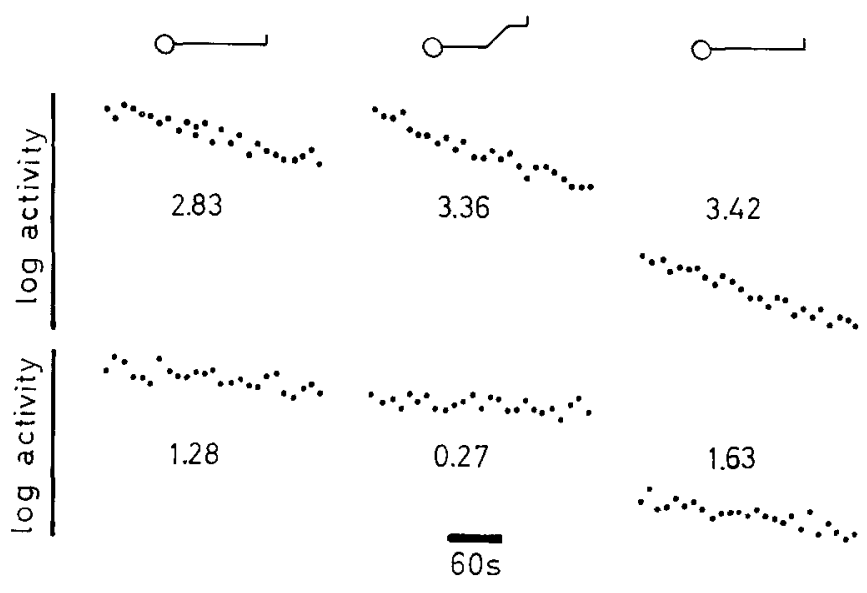

Fig. 1. Two sets of measurements (count rates) in muscle tissue showing (upper panel) normal and (lower panel) impaired autoregulation. In the centre measurement of each set the leg was raised $40 \mathrm{~cm}$. The numbers are the washout rate constants $(\mathrm{k} / \mathrm{min})$ : 100 for each slope
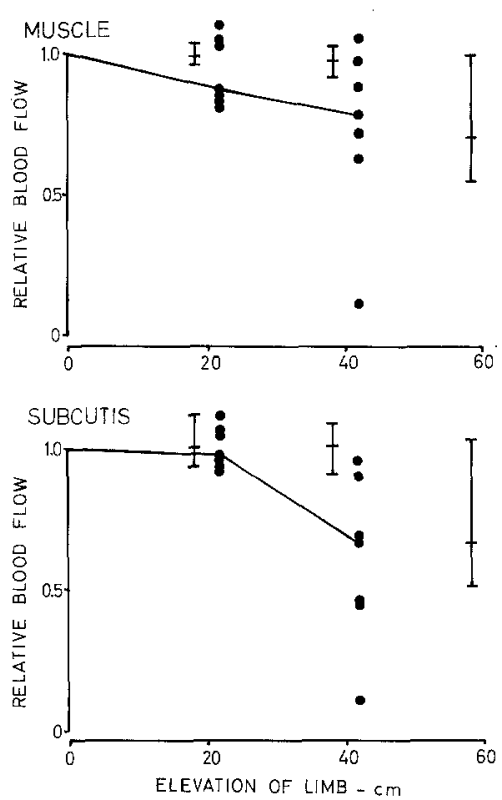

Fig. 2. Relative blood flow against height of elevation of the limb for muscle (upper panel) and subcutaneous tissue (lower panel). The vertical bars represent the range and median values for eight normal subjects. The lines join the median values for the diabetic subjects

waiting for the hyperaemia of the injection to subside (60 and $20 \mathrm{~min}$, respectively) measurements were started. The impulses were detected by a NaI scintillation detector (Mölsgaard, Hörsholm, Denmark $33 \mathrm{~mm}$ diameter, $25 \mathrm{~mm}$ thick) connected with a spectrometer (Meditronic, Copenhagen, Denmark) with a window set around the $81 \mathrm{kev}$ $\gamma$-photo peak of ${ }^{133} \mathrm{Xe}$. The detector was placed about $25 \mathrm{~cm}$ from the limb which was immobilized with a vacuum fixation pillow. In each site measurements of the clearance of the isotope were made with the limb horizontal (depot at heart level) and then successively at 20,0,40, 0,40 and $0 \mathrm{~cm}$ above heart level. When the limb was elevated care was taken to avoid pressure over the popliteal vein. The time between changing position and starting the next set of measurements was about $5 \mathrm{~min}$. The count rates obtained were about $500-1000 / \mathrm{s}$ from muscle and about $100-5000 / \mathrm{s}$ from SC tissue. Background counts were $<20 / \mathrm{s}$.

A digital count of the impulses recorded each $10 \mathrm{~s}$ was obtained. The washout rate constant $(\mathrm{k} / \mathrm{min})$ was determined as the regression coefficient calculated by the method of least squares from the logarithm of the count rate corrected for background activity. Relative blood flow at each height above heart level was calculated as the kvalue obtained above heart level divided by the mean of the $k$-value obtained at heart level immediately before and after the measurement (Fig. 1). At $40 \mathrm{~cm}$ elevation the mean of the two sets of measurements was used.

\section{Statistical Methods}

Non-parametric statistical methods have been used. Results are given as the median (range). Differences between groups have been tested using the randomisation test for independent samples.

\section{Results}

\section{Normal Subjects}

Both in skeletal muscle and subcutaneous tissue blood flow always remained within $10 \%$ of the control value when the limb was elevated to $40 \mathrm{~cm}$ above heart level.

\section{Diabetic Subjects}

There was a reduced capacity for autoregulation in both skeletal muscle and subcutaneous tissue (Fig.2). The relative blood flow when the limb was raised 20 and $40 \mathrm{~cm}$ were for muscle: $86 \%(82 \%-110 \%)$ and $79 \%$ $(11 \%-106 \%)$ and for SC tissue: $96 \%(91 \%-130 \%)$ and $66 \%(12 \%-95 \%)$, respectively. For both skeletal muscle and subcutaneous tissue, the median relative blood flow at $40 \mathrm{~cm}$ elevation was less than in normal subjects $(p<$ 0.05 and $p<0.001$ respectively).

In each site the same two patients were able to maintain the blood flow within the normal range at $40-\mathrm{cm}$ elevation. In four diabetic patients the blood flow in muscle, at $20-\mathrm{cm}$ elevation, was less than that seen in any of the normal subjects.

\section{Discussion}

The major novel observation in our study is the demonstration of impaired autoregulation of blood flow in the skeletal muscle and subcutaneous tissue in long-term Type 1 diabetic patients with microangiopathy. It should be noted that we have only tested the response to decreased perfusion pressure. No patient had evidence of large vessel disease affecting the lower limbs and arterial hypertension was not present. During the test arterial blood pressure in the limbs was reduced in proportion to the height of the elevation above heart level. In the upper limb the venous pressure remains constant at close to $0 \mathrm{mmHg}$ when the limb is elevated [3]. It is likely that the veins in the lower limb behave identically. Elevation of the limb by $40 \mathrm{~cm}$ reduced the perfusion pressure by approximately $30 \%$. If there had been a complete loss of autoregulation so that the flow was passively dependent on perfusion pressure, it 
would be expected that the blood flow would fall by the same proportion. The observed median decreases in blood flow, 21\% for muscle and 34\% for subcutaneous tissue were close to the predicted pressure-passive values. It should be mentioned that a wide variation in responses in both tissues ranging from normal to severely impaired autoregulation was demonstrated. It is possible that this variation can be explained by varying degrees of arteriolar disease. However tissue biopsy was not performed.

The basis for these abnormalities might involve either structural changes (e.g. arteriolar hyalinosis) and/ or functional disturbance of smooth muscle so that reactivity was impaired. We have recently produced evidence of reduced distensibility of the microcirculation (arterioles) in muscle in a similar group of long-term Type 1 diabetic patients with clinical microangiopathy [16]. The same structural changes could underly both abnormalities. Descriptions of histological changes [17, 18] have concentrated on abnormalities of the tunica intima, although it is conceivable that intimal disease could reduce the effectiveness of vasodilatation while vasoconstriction could be normal. However, the maximum blood flow in muscle was not reduced following ischaemic exercise in a similar group of diabetic patients $[16,19,20]$, indicating that the vascular bed reacted normally to a strong metabolic stimulus. This points to a more specific lesion of the mechanisms underlying the autoregulatory response: hyaline deposits of the arteriolar wall might impair myogenic responses or there may be local metabolic disturbances which affect arteriolar smooth muscle activity.

Our study provides further evidence of disturbed microcirculatory control in diabetes. Autonomic neuropathy causes a reduction in response both to reflexlyinduced thermoregulatory stimuli [21] and to local increases in venous pressure [22]. The changes we have observed are probably due to local structural or functional disturbances in the arterioles which are independent of autonomic neuropathy. The observed impairment of autoregulation may indicate that reduction of the local arterial perfusion pressure due to proximal occlusive arterial disease causes a larger fall in the perfusion in skeletal muscle and skin in the diabetic patients than in atherosclerotic patients without diabetes. Consequently tissue ischaemia may develop earlier in diabetic patients with proximal occlusive arterial disease.

Further studies including tissue biopsy are necessary to determine whether our findings can be related to histological changes. However, we believe that we now have methods for assessing microvascular function and these may allow a reassessment of the clinical importance of microvascular disease in the leg.

Acknowledgements. IF was in receipt of a Danish Government Scholarship. This study was supported by grants from the Danish Diabetes Association and The Danish Medical Research Countil. The skilful technical assistance of U.M.Schmidt is gratefully acknowledged.

\section{References}

1. Lassen NA (1964) Autoregulation of cerebral blood flow. Circ Res 14-15 (Suppl 1): 301-304

2. Haynes BW, Morris GC, Moyer JH, Snyder HB (1953) Effects of controlled hypotension on glomerular filtration and renal plasma flow in man. Surg Forum 4: 443

3. Henriksen O, Nielsen SL, Paaske WP (1973) Autoregulation of blood flow in human adipose tissue. Acta Physiol Scand 89: 531-537

4. Folkow B (1949) Intravascular pressure as a factor regulating the tone of small vessels. Acta Physiol Scand 17: 289-310

5. Johnson PC (1977) The myogenic response and the microcirculation. Microvasc Res 13:1-18

6. Berne RM (1964) Metabolic regulation of blood flow. Circ Res 14-15 (Suppl 1): 261-267

7. Berne RM, Rubio R, Dobson JG (1971) Adenosine and adenine nucleotides as possible mediators of cardiac and skeletal muscle blood flow regulation. Circ Res 28 (Suppl 1): 115-119

8. Hilton SM (1971) A new candidate for mediator of functional vasodilatation in skeletal muscle. Circ Res 28 (Suppl 1): 70-72

9. Kjellmer I (1965) The potassium ion as a vasodilatator during muscular exercise. Acta Physiol Scand 63: 460-468

10. Granger HG, Goodman AH, Granger ON (1976) Role of resistance and exchange vessels in local microvascular control of skeletal muscle oxygenation in the dog. Circ Res $38: 379-385$

11. Kontos HA (1971) Role of hypercapnic acidosis in the local regulation of blood flow in skeletal muscle. Circ Res 28 (Suppl1): 98-105

12. Bentsen N, Larsen B, Lassen NA (1975) Chronically impaired autoregulation of central blood flow in long-term diabetics. Stroke 6 : 497-502

13. Dandonna P, James IM, Woolard ML, Newrury P, Beckett AG (1979) Instability of cerebral blood flow in insulin-dependent diabetics. Lancet 2: 1203-1205

14. Brøchner-Mortensen J (1972) A simple method for the determination of glomerular filtration rate. Scand J Clin Lab Invest 30: 271-274

15. Lassen NA, Lindbjerg IF, Munck O (1964) Measurement of blood flow through skeletal muscle by intramuscular injection of Xenon $^{133}$. Lancet 1: 686-689

16. Faris I, Agerskov K, Henriksen O, Lassen NA, Parving H-H (1982) Decreased distensibility of a passive vascular bed in diabetes mellitus: an indicator of microangiopathy. Diabetologia 23: 411-414

17. Goldenberg S, Alex M, Joshi RA, Blumenthal HT (1959) Nonatheromatous peripheral vascular disease of the lower extremity in diabetes mellitus. Diabetes 8: 261-273

18. Stary HC (1966) Disease of small blood vessels in diabetes mellitus. Ann J Med Sci 180: 149-171

19. Munck O, Lindbjerg IF, Binder C, Lassen NA, Trap-Jensen J (1966) Skeletal muscle blood flow in diabetic patients determined by intramuscular injection of Xenon ${ }^{133}$. Diabetes 15 : 323-326

20. Neubauer B (1978) Tilted and non-tilted post-ischaemic exercise blood flow in the legs of long-term diabetic and normal subjects. Diabetologia 15: 9-11

21. Moorhouse JA, Carter SA, Dovie J (1966) Vascular responses in diabetic peripheral neuropathy. Br Med J 1: 883-888

22. Hilsted J (1979) Decreased sympathetic vasomotor tone in diabetic orthostatic hypotension. Diabetes 78: 970-973

Received: 18 January 1983

and in revised form: 13 June 1983

\section{Dr. I. Faris}

Department of Surgery

Royal Adelaide Hospital

Adelaide, South Australia 5000

Australia 